Max-Planck-Institut für demografische Forschung

Max Planck Institute for Demographic Research

Konrad-Zuse-Strasse 1 - D-18057 Rostock · GERMANY

Tel +49 (0) 3812081 - 0; Fax +49 (0) 3812081 - 202;

http://www.demogr.mpg.de

MPIDR WORKING PAPER WP 2007-023

JUNE 2007

\title{
Women's Status and Reproductive Preferences in Eritrea
}

Gebremariam Woldemicael (gebre_wm@yahoo.com))

This working paper has been approved for release by: Hill Kulu (kulu@ demogr.mpg.de)

Deputy Head of the Laboratory of Contemporary European Fertility and Family Dynamics.

(C) Copyright is held by the authors.

Working papers of the Max Planck Institute for Demographic Research receive only limited review. Views or opinions expressed in working papers are attributable to the authors and do not necessarily reflect those of the Institute. 


\title{
Women's Status and Reproductive Preferences in Eritrea
}

\author{
Gebremariam Woldemicael $^{1}$
}

\begin{abstract}
The importance of women's decision-making autonomy has recently emerged as a key factor in influencing reproductive preferences and demand for family planning in developing countries. In this study, the effect of direct indicators of women's decision-making autonomy on fertility preferences and ever-use of modern contraception is examined using logistic regression models with and without proxy indicators. The results provide evidence that different dimensions of women's autonomy influence the outcome variables differently in terms of magnitude and statistical significance. Particularly, women's final say in decisions regarding day-today household purchases and spousal communication about family planning are influential predictors of fertility preferences and ever-use of modern family planning methods. At the same time, results show that the effects of women's education on fertility preferences are not always significant although it has significant roles in affecting women's decision-making autonomy. Women's household economic situation has always significant effects on women's autonomy as well as on fertility preferences and ever use of contraception. Thus, a complete explanation of the relationship between women's autonomy and reproductive preferences must recognize the effects of both proxy and direct indicators of women's autonomy. Interventions are needed to improve women's decision-making autonomy and strengthen their negotiating capacity for family planning use if an increased desire to limit fertility is to be attained.
\end{abstract}

\footnotetext{
${ }^{1}$ Associate Professor of Demography, University of Asmara, Eritrea. E-mail: gebre_wm@yahoo.com This study was made while the author was a guest researcher at the Max Planck Institute for Demographic Research in Rostock, Germany, during December 2006-April 2007
} 


\section{Introduction}

The importance of women's household decision-making autonomy has long been recognized as an important factor in influencing reproductive behavior. In the Program of Action of the International Conference on Population and Development (ICPD) held in Cairo in 1994 it was, for example, stated that one important way to reduce high-fertility in developing countries was by means of improving women's status, and it called for the advancement and empowerment of women (UN 1995). More recently, in the meeting held in Beijing in 1999 (ICPD+5 Review of Progress since the Cairo Conference), it was stated that improvements in women's status are important factors to enable women to control their own fertility.

However, although improvement in women's status is a key factor in reproductive preferences and family planning programs, its relative importance is not clearly understood as many researchers fail to make distinction between the direct measures of women's decision-making autonomy and proxy indictors such as education, employment or household wealth. In addition, in many earlier studies, most of the attention was directed to the impact of proxy variables on reproductive behavior through the proximate determinants of fertility, particularly age at marriage, contraceptive use, and duration of breastfeeding (Okojie 1995). The various aspects of women's decision-making autonomy, such as women's freedom of movement, their participation in decision-making, their ability to visit their relatives or friends, their communication about family planning with partner, and their access to and control over resources have often been overlooked. Studies that have used these direct measures of women's decision-making autonomy argue that women's decisionmaking autonomy influences reproductive preferences so strongly that they can not be ignored (Qiaozhuan and Chuzhu 1997). Several studies indicate that changes in education and labor force participation do not necessary translate into improvements in women's status (Balk 1997; Jejeebhoy and Sathar 2001; Malhotra et al. 1995) and they do not fully involve all dimensions of women's decision-making roles in the household or society (Mason 1994). Thus, simply using education or employment as proxy indicators for women's status may underestimate or estimate incorrectly the total effects of other variables on fertility preferences or fertility (e.g., Vlassoff 1992).

Moreover, fertility preferences are affected by the normative pressure of society, particularly in patriarchal societies or where there is male dominance, like in most sub-Saharan African countries. In such circumstances, it is unrealistic to assume that fertility preferences and demand for family planning are solely determined by individual proxy indicators. Even educated or employed women may fail to translate their fertility preferences into actual behavior because of male dominance, if their husbands are opposed. The lag in fertility decline and contraceptive use in a number of developing countries is often attributed to gender inequality and patriarchy which encourages high fertility through the separate roles it assigns to men and women (Balk 1994; Basu 1992; Caldwell 1986; Dharmalingam and Morgan 1996; Morgan and Niraula 1995). Improved autonomy of women is an important determinant of fertility and hence it is only with the inclusion of women's autonomy in research that determinants of fertility and fertility preferences can be understood. Failure to include the more direct autonomy measures in research and programs for reproductive behavior in sub-Saharan Africa may have serious implications, not only for family planning, but also for the reliability of fertility estimates that include only proxy 
variables. Thus, any detailed and comprehensive analysis of factors influencing reproductive preferences or behaviors should include both women's decision-making autonomy and proxy variables.

While direct measures of autonomy have emerged as important indicators of women's agency and are recognized as important factors to reduce fertility and family size in many other developing countries, reproductive preferences have not been studied in relation to women's status for Eritrea. Very little is known about the effects of various women's autonomy indicators on reproductive behavior there. This paper examines whether women's decision-making autonomy affects fertility preferences and contraceptive use in Eritrea using data from the 2002 Eritrea Demographic and Health Survey. We study the relation of those indicators with reproductive behaviour and disentangle to what extent the relative importance of the direct autonomy variables is independent of the influence of the proxy indicators. In particular, we hypothesize that women who are able to participate in household decision-making, who have the ability to discuss family planning with their partner, who have freedom to visit families and friends, and who feel that wife beating is not justified for any reason are more likely to wish to limit childbearing and to have ever-used modern contraception than women who do not possess these freedoms.

\subsection{The concept of women's status}

Even though the concept of women's status is widely used in demographic studies, notably in reproductive preferences and health studies, there is no single accepted definition that represents it or that captures the multiple dimensions of women's position (Mason 1984). Alternative terms such as women's empowerment, female autonomy, women's position, gender inequality, access to and control over resources and prestige are all frequently used interchangeably in the literature to define women's status (Mason 1986). For example, women's status has been examined by comparing women's versus men's position across a variety of socioeconomic and demographic factors (Kishor and Neitzel 1996). Other studies referred specifically to women's relative prestige (Mason 1989), and still others used proxy indicators such as women's education (e.g., Weinberger et al. 1989) and income or employment (e.g., Safilios-Rothschild 1990; Jejeebhoy 1991) to define the status of women. Dyson and Moore (1984) defined autonomy or status as the ability to manipulate ones personal environment as a basis for decision-making about personal concerns. However, more recent studies (e.g., Balk 1994; Morgan and Niraula 1995) have divided autonomy into different dimensions such as women's participation in decision-making, their physical freedom of movement, their ability to visit their relatives or friends, and their access to resources. This type of definition regards women's status as a multiple or combination of different components which vary from one society to another and it has recently been used in studies of fertility and reproductive health (e.g., Tfaily 2004; Basu and Koolwal 2005; Desai and Johnson 2005). The measures of women's autonomy we consider here represent various domains that have been identified in the literature as important for women's reproductive preferences. They include the extent to which women are autonomous in decision making regarding large and daily household purchases, the degree to which they can go to visit relatives or friends without their husbands or seniors permission, the extent of women's interactions/communications with their husbands regarding family planning, and the extent of women's refusal to wife beating. 


\subsection{Data and methods}

The data used in this study come from the Eritrea Demographic and Health Survey (EDHS) conducted under the auspices of the International Comparative Program of the Demographic and Health Surveys in 2002. This survey is the second nationally representative survey in Eritrea and enquires about household members' characteristics including questions on women's decision-making responsibilities in the household. Individual women of reproductive age (15-49 years) are interviewed in face to face on their background characteristics as well as on their fertility and fertility preferences, contraceptive use, and use of maternal and child health services. Fertility and child mortality data are obtained through a birth history, while nutritional status of children and women is determined through anthropometry. This survey interviewed 8,754 women aged 15-49. Most of our analyses are centered on married women to target the main points in which women were asked questions regarding the degree of final say in decision-making they have in the household, as well as the degree to which women agree or disagree with negative gender norms (e.g., wife beating).

The three main dependent variables are:

- Fertility preferences as measured by desire for no more children

- Fertility preference as measured by desired family size (ideal number of children), and

- Ever-use of modern contraceptive methods.

The primary independent variables of interest are: Variables reflecting women's involvement (final say) in decisions regarding three domains of household life (making large household purchases, making day-to-day household purchases, and visits to family and friends). In addition, two other direct measures of women's autonomy, women's attitude toward wife beating and spousal discussion on family planning, are used.

These women's autonomy profiles are often correlated with a number of proxy measures of women's autonomy including their education, household wealth, and employment (Kishor 2005). Thus, our analysis controlled for these proxy indicators of women's autonomy as well. We also control for the number of living children the woman has and urban-rural residence. There is no time disparity between measures of women's autonomy and fertility preferences because both types of measures are collected at the time of the survey.

To measure the impact of women's decision-making autonomy on fertility desire and ever-use of modern contraception, we estimated bivariate and multivariate logistic regression models, using SPSS software.

Bivariate analyses are used to describe the nature and magnitude of fertility preferences according to the different proxy and autonomy indicators of women's status. To examine in-depth the association between women's autonomy and fertility preferences and contraceptive use, multivariate logistic regression models are used. We estimate two models for each outcome variable. The first model contains women's decision-making autonomy only and the second model adds the proxy indicators and other control variables to determine the relative importance of each of the autonomy indicators in relation to the proxy indicators. 


\subsection{Description of variables}

In addition to information on women's educational attainment, employment status, household assets, and other socio-demographic characteristics, the 2002 EDHS collected information on direct measures of women's autonomy. In particular, questions were asked on women's participation in specific household decisions and in their attitudes towards wife beating. Among an array of questions designed to measure women's position, the EDHS asked women the following: Who in your family usually has final say on the following decisions:

Making large household purchases?

Making household purchases for daily needs?

Visits to family or relatives?

Five options were offered as replies to each question in the survey: 1) respondent alone, 2) respondent and husband/partner, 3) respondent and other person in the household, 4) husband alone, 5) someone else. To gain larger data in each category, we merged categories 2 and 3, and 4 and 5, respectively.

Another variable is created from answers to questions based on women's agreement on whether a husband would be justified in beating his wife in each of the following situations: if the wife burns the food, if she argues with him, if she goes out without informing him, if she neglects the children, or if she refuses to have sex with him. Our summary measure of women's attitude has two categories: "no" if the woman disagrees with all the reasons and "yes" if she agrees with at least one of them. The information on attitudes towards wife beating is mainly used to determine the extent of women's acceptance of norms that subordinate their bodily integrity and sexuality to men, is of particular relevance to demographic and health programs. Spousal communication about family planning is included to measure the extent of women's participation in discussions of fertility control and family planning affairs at the household level. This variable has also two categories: "yes" if the woman has ever discussed and "no" if she has never discussed these issues.

The proxy measures of women's autonomy included in this study are: women's educational attainment, employment, and household economic status. Residence and number of living children are used as control variables. Women are classified into three categories according to their educational attainments: no education, primary, and secondary or higher education. Employment is measured by a dichotomous variable: employed and not employed at the time of the survey. Household economic status is based on information on household ownership of a number of consumer items as well as dwelling characteristics such as source of drinking water, sanitation facilities and type of material used in flooring (NSEO and ORC Macro Inc. 2003). Since the number of children a woman has influences her fertility preferences and contraceptive use, we have included number of living children as a control variable.

Fertility preferences are measured through two variables: the desire for additional children and desired (ideal) family size. Desire for more children is used to measure the extent to which married women wish to limit childbearing. It is based on women's response to the following questions: 1) For non-pregnant women, 'would you like to have a (another) child, or would you prefer not to have any (more) children?' 2) For pregnant women, 'Aside from the child you are currently pregnant with, do you want 
to have any more children?' Desired family size (or ideal number of children) is constructed from respondents' responses to the following questions: 1) for respondents who had no children: 'If you could choose exactly the number of children to have in your whole life, how many would that be?' 2) Respondents with children were asked, 'If you could go back to the time you did not have any children and choose exactly the number of children to have in your whole life, how many would that be?' In our study, this variable is defined in two categories: desired family size of less than five and five or more.

\section{Status of women in Eritrea}

In order to place in context this study of fertility preference in Eritrea, we first present briefly the background profiles of women including their participation in political and public decision-making, educational achievement, employment and domestic decision-making affairs.

During the past decades, effort has been made to alleviate the situation of women in Eritrea. Particularly since independence (1993), the government of Eritrea together with international and national organizations has set the stage for women to participate in building the country. Women workers who were threatened with expulsion from work upon delivery during the colonial regime were granted sixty days paid maternity leave, and the right of equal pay for equal work is clearly stated in the labor proclamation of Eritrea. Far more, the government has taken measures in areas of inheritance of property and land, eradication of illiteracy, promulgation of new labor law and creation of institutional framework for mass participation of which the establishment of National Union of Women's Association is one. These measures are oriented towards tackling the problems of underdevelopment at its roots and towards fully integrating the female population in development efforts.

However, although the progress made after independence to alleviate women's participation and rights in Eritrea may not be reversed to the traditional role of women, we can not say that women's full participation and rights in Eritrea are secured. Even though the Civil Code stipulates that women enjoy equal rights with men in all spheres of life, women still have less access than men to education, employment, and property ownership. Especially, in the rural areas, women are much less likely than men to be politically active and to participate in decision making, and more likely to be vulnerable to different types of cultural or traditional harmful practices such as early and arranged marriages, female circumcision, etc. Legal status of women is affected by religious/customary laws and cultural perceptions of the society that assumes women as inferior to men. For example, the Civil Code provides that a man or a woman who has not attained the full age of eighteen years may not contract marriage. However, in rural areas, it is customary for marriage arrangements to be made by parents when the girl is scarcely more than a child. In addition, the tradition of men marrying women younger than themselves is culturally supported and marital relationships based on paternal roles resulting in male domination is propagated. Childless marriages are perceived as unstable and childless women face severe stigma. In addition, in most cases, the husband is the head of the household and he has authority over his wife and children. The wife on the other hand is 
subordinated to the husband and his kinsfolk and she is expected to operate on their terms.

Even though male dominance and female dependency on males is strong and continues to persist in Eritrea, it is not yet clear whether they systematically elicit different demands for children or contraceptive use. However, some studies (e.g., Caldwell and Caldwell 1985) noted that the low involvement of women in decisionmaking process regarding childbearing is one of the main reasons why fertility is still high in sub-Saharan Africa. With a desire for large family size, the desire to adopt modern contraception for limiting childbearing will be low. In Nigeria, some studies show that women's sole decision making and joint decision-making on fertility desires are higher among groups in which women's status is higher (Kritz and Makinwa-Adebusoye 1999; Makinwa-Adebusoye and Kritz 1997).

It is worth mentioning here that since the recent border conflict (1998-2000) with Ethiopia might have negatively affected the socio-economic status and decisionmaking power of women in Eritrea, caution must be exercised in interpreting the results related to women's situation in general. Access to education, health care, employment and participation in other activities might have deteriorated because of the border conflict which diverted human and financial resources to national defense. Added to this situation is the worsening inflation that affected living standards of the population. For example, the inflation rate increased from $17 \%$ in 1998 to $27 \%$ in 2000 (GSE and UNICEF 2001). The war also resulted in massive displacements of people and in military mobilization of all productive young Eritreans (mostly men) aged 18-40 years, which in turn caused shortage of manpower and high spousal separation.

\subsection{Participation in political decision making}

In spite of the efforts made to improve women's status, women have limited political participation in terms of representation in parliament and public administration. Table 1 shows the distribution of women's participation in national parliament and other government posts as of 2002. Out of the total posts, $13 \%$ were females. The proportion of women parliamentarians was $22 \%$. Compared to other developing countries, this appears fairly high (PRB 2005). The proportion varies from as low as $10 \%$ in Northern Africa and Southern and Western Asia to as high as about $43 \%$ in Sweden (PRB 2005). Table 1 also shows that women participate in many levels of government administration, even though their participation is smaller than for men.

Table 1: Percent distribution of women in political decision making, Eritrea 2002

\begin{tabular}{lcc}
\hline Post & Percent female & Total (N: both sexes) \\
\hline National parliament & 22 & 150 \\
Ministers & 12 & 17 \\
Directors & 7 & 156 \\
Regional/sub-regional governors & 5 & 59 \\
District administrators & 23 & 13 \\
Ambassadors & 11 & 18 \\
\hline Total & $\mathbf{1 3}$ & $\mathbf{4 1 3}$ \\
\hline
\end{tabular}

Source: CPA of Eritrea, 2002 


\subsection{Educational attainment}

Education is recognized as a key factor for empowering women. The 1994 Cairo consensus emphasizes that education is important for everyone, but especially significant for girls and women (UN 1995). This is true not only because education increases women's income and utilization of health care and other social services, but also helps them to know their rights and gain confidence to claim them. Women's education is also hypothesized to delay age at marriage, reduce preferences for children (Cochrane 1979) and to increase use of modern contraceptive methods and health care facilities (Okojie, 1995).

In Eritrea, enrollment rates for girls have always remained lower than those of boys. The 2002 EDHS survey shows that more than one-half of female household members have never attended school compared with $39 \%$ of males (Figure 1).

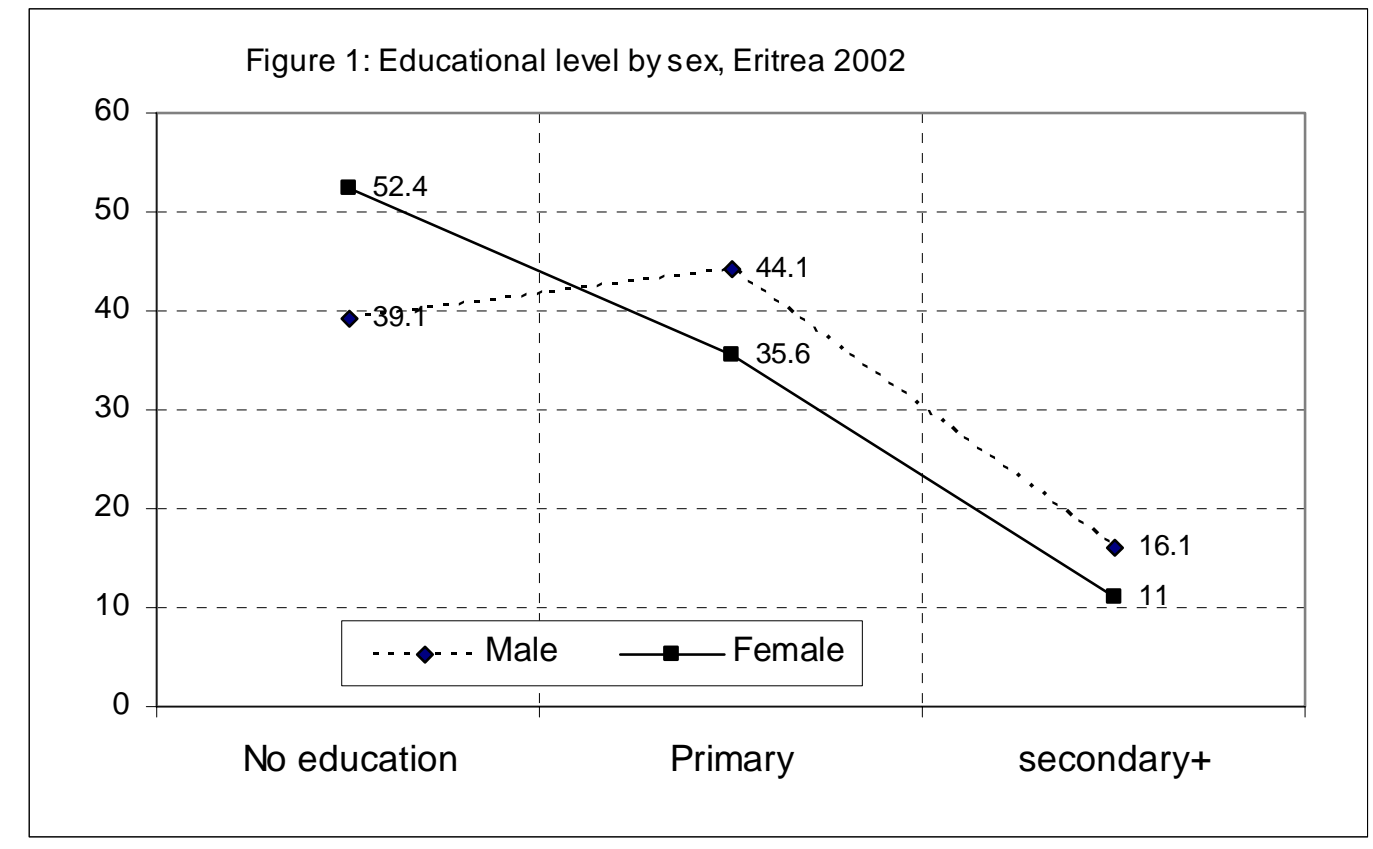

However, although there is gender disparity in education there has been an increase in educational attainment for both sexes. Figure 2 shows a decline in the proportion of household members without any formal education among younger cohorts. For example, the proportion of women with no education declines from $95 \%$ at age 65 and above to $21 \%$ at age 10-14 (Figure 2). The EDHS also indicate that there have been considerable improvements since the 1995 EDHS in educational attainment among both males and females (NSEO and ORC Macro Inc. 2003). 


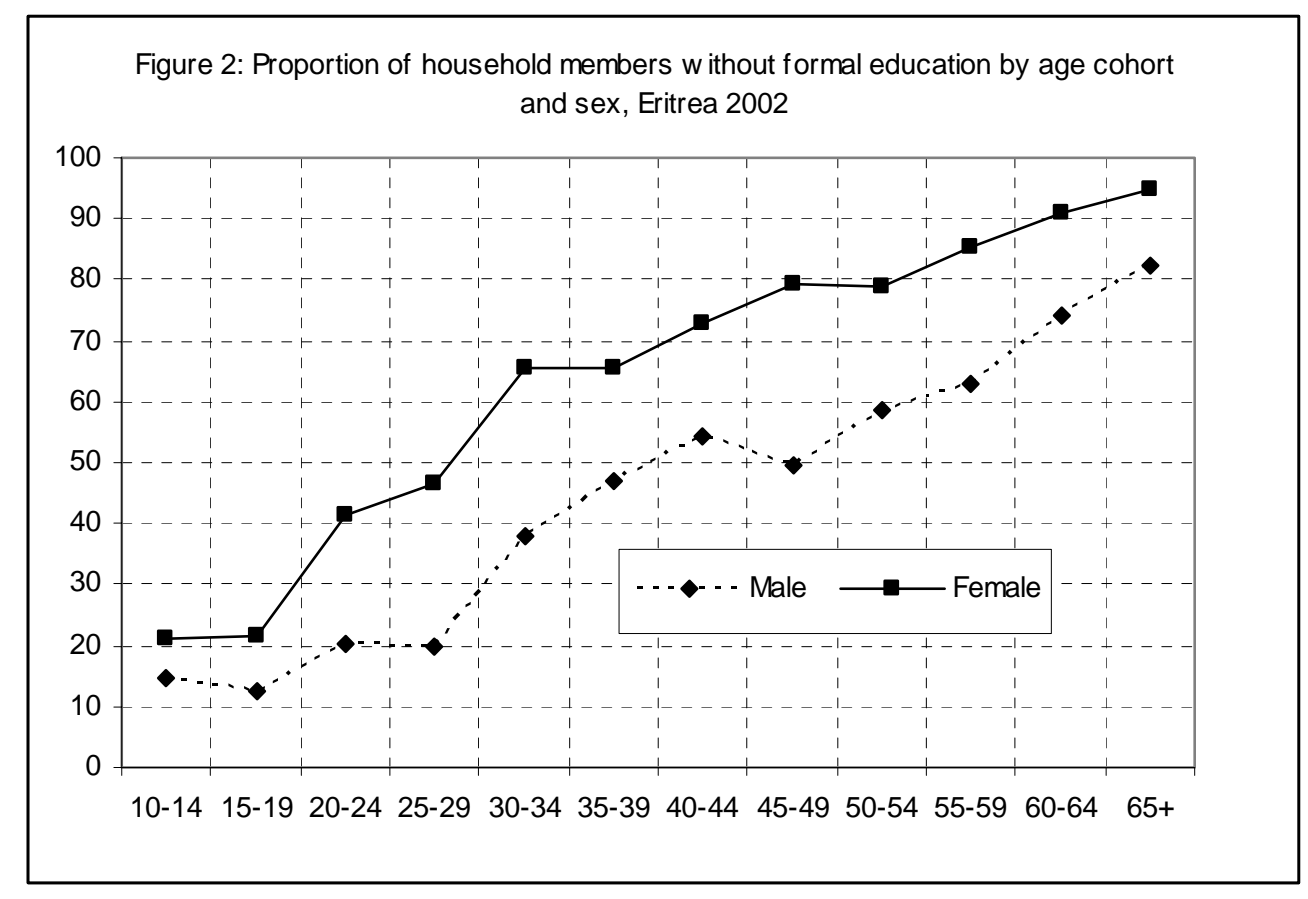

Table 2 shows the educational attainment of women at reproductive ages by age and residence. It is observed that the percentage of women who have never attended school is much higher than the percentage of women with primary and secondary education. Women's education in Eritrea varies by women's age as well as by place of residence. As expected, women in the oldest age groups (40 years and above) have the lowest level of education. An important finding is the high proportion (50\%) at the primary level for the youngest age group. Residence differences in education are very pronounced, with a disadvantage in the rural areas. It is evident from Table 2 that $71 \%$ of women in rural areas have never attended school compared with only $23 \%$ in the urban areas.

Table 2: Educational attainment of women by age and residence (\%), Eritrea 2002

\begin{tabular}{lccccr}
\hline $\begin{array}{l}\text { Background } \\
\text { variables }\end{array}$ & No education & Primary & Secondary+ & Total & $\begin{array}{r}\text { Number of } \\
\text { women }\end{array}$ \\
\hline $\begin{array}{l}\text { Age of woman } \\
15-19\end{array}$ & 21.2 & 49.8 & 29.0 & 100.0 & 2001 \\
$20-24$ & 42.2 & 31.5 & 26.3 & 100.0 & 1454 \\
$25-29$ & 47.2 & 28.0 & 24.8 & 100.0 & 1543 \\
$30-34$ & 65.0 & 20.1 & 14.9 & 100.0 & 1109 \\
$35-39$ & 65.4 & 21.5 & 13.1 & 100.0 & 1085 \\
$40-44$ & 72.9 & 17.4 & 9.7 & 100.0 & 828 \\
$45-49$ & 79.3 & 16.8 & 4.0 & 100.0 & 734 \\
Residence & & & & & \\
Urban & 22.7 & 36.2 & 41.2 & 100.0 & 3767 \\
Rural & 70.8 & 25.0 & 4.2 & 100.0 & 4987 \\
\hline Total & $\mathbf{5 0 . 1}$ & $\mathbf{2 9 . 8}$ & $\mathbf{2 0 . 1}$ & $\mathbf{1 0 0 . 0}$ & $\mathbf{8 7 5 4}$
\end{tabular}




\subsection{Employment status}

Among the important indicators and cause of changes in women's status is their participation in the labor force. Women who work outside the home, are presumed to have more control over household resources, increased awareness of the world outside the home, and consequently greater control over reproductive decisions (Gage 1995; Mason 1986). Whether women actually achieve higher status through employment, however, depends on the type and location of the work, whether cash is earned and cultural norms that determine the acceptance of women working outside the home.

Table 3 presents the work pattern of women, according to selected background variables. Overall, only one-fourth of women were working during the survey time. The data show not much difference according to age, although older women are more likely to be employed than younger women. Women are more than twice as likely to be employed in urban areas as in rural areas. There is a clear difference in the work status of women according to their level of educational attainment. Among women with primary education, the proportion of women who are working is $20 \%$, however this proportion rises to $35 \%$ among women with the highest level of education. Divorced/separated or widowed women are most likely to be employed (43\%) while married women are least likely to be employed (15\%). Women with five or more children are less likely to be working than women with fewer or no children.

Table 3: Percent distribution of women by current work status, according to selected background variables

\begin{tabular}{lcccr}
\hline $\begin{array}{l}\text { Background } \\
\text { variables }\end{array}$ & Not working & Working & Total & $\begin{array}{r}\text { Number of } \\
\text { women }\end{array}$ \\
\hline Age of woman & & & & \\
$15-19$ & 89.9 & 10.1 & 100.0 & 1999 \\
$20-24$ & 81.6 & 18.4 & 100.0 & 1454 \\
$25-29$ & 75.0 & 25.0 & 100.0 & 1540 \\
$30-34$ & 78.6 & 21.4 & 100.0 & 1109 \\
$35-39$ & 75.1 & 24.9 & 100.0 & 1084 \\
$40-44$ & 76.6 & 23.4 & 100.0 & 826 \\
$45-49$ & 75.6 & 24.4 & 100.0 & 733 \\
Residence & & & & \\
Urban & 71.3 & 28.7 & 100.0 & 3761 \\
Rural & 86.8 & 13.2 & 100.0 & 4984 \\
Education & & & & \\
No education & 86.3 & 13.7 & 100.0 & 4382 \\
Primary & 79.7 & 20.3 & 100.0 & 2609 \\
Secondary & 65.5 & 34.5 & 100.0 & 1754 \\
Marital status & & & & \\
Currently married & 85.5 & 14.5 & 100.0 & 5727 \\
Divorced/widowed & 56.6 & 43.4 & 100.0 & 975 \\
Never married & 76.5 & 23.5 & 100.0 & 2043 \\
Number of living children & & & & \\
0 & 79.5 & 20.5 & 100.0 & 3018 \\
1-2 & 77.8 & 22.2 & 100.0 & 2284 \\
3-4 & 78.4 & 21.6 & 100.0 & 1768 \\
5+ & 86.4 & 13.6 & 100.0 & 1675 \\
\hline Total & $\mathbf{8 0 . 2}$ & $\mathbf{1 9 . 8}$ & $\mathbf{1 0 0 . 0}$ & $\mathbf{8 7 4 5}$ \\
\hline
\end{tabular}




\subsection{Women's participation in decision-making}

To assess how the direct measures of women's autonomy vary by other background variables, percentage distribution of women's involvement in decision-making, according to some selected characteristics of women is presented in Table 4. Since participation in decision-making refers to women's status relative to their partner, only married women are considered here. Overall, 59, 69 and 75\% of women participated in the decisions for making large purchases, making daily purchases and visiting family or relatives, respectively. Compared with findings from some other African settings, these figures appear to be high. For instance, a study in Northern Nigeria indicates that $85 \%$ of all household decisions, including grain and animal sales, medical care of household members, clothing purchases and investment in education of children are made by men (Robson 1995). It is evident from Table 4 that involvement in decision-making varies by the socio-demographic characteristics of women. For example, younger women tend to be less involved in all dimensions of autonomy than older women. Women living in urban areas and those more educated have higher participation in household decision making than their counterparts living in rural areas and with no education, respectively. Currently working women and those with higher household economic status also appear to have higher final say in decision making.

Overall, 27\% of women feel that wife beating is never justified (Table 4). Women at older ages are more inclined to agree with at least one of the reasons justifying a husband beating his wife. This may be that younger women have more modern views and are more sensitive to their status. Considerable differences in women's views are observed with the increase in educational attainment, especially at secondary or more education. Women with secondary or higher education are more than twice as likely to disagree with wife beating than women with no education. However, it is surprising that one half of women with secondary or more education still agree that a husband can beat his wife. Women with higher economic status are more likely to disagree with wife beating than women with low economic status. Employment and being household head do not make much difference in attitudes towards wife beating. 
Table 4: Percent of women who say that they alone or jointly have the final say in specific decisions and who disagree with wife beating, according to selected background variables

\begin{tabular}{|c|c|c|c|c|c|}
\hline \multirow[b]{2}{*}{$\begin{array}{l}\text { Background } \\
\text { variables }\end{array}$} & \multicolumn{3}{|c|}{ Involved in decision making } & \multirow[b]{2}{*}{$\begin{array}{l}\text { Disagreement } \\
\text { with at least } \\
\text { one specified } \\
\text { reason of } \\
\text { wife beating* }\end{array}$} & \multirow[b]{2}{*}{$\begin{array}{r}\text { Number of } \\
\text { women }\end{array}$} \\
\hline & $\begin{array}{l}\text { Making } \\
\text { large } \\
\text { purchase }\end{array}$ & $\begin{array}{c}\text { Making } \\
\text { daily } \\
\text { purchase }\end{array}$ & $\begin{array}{l}\text { Visit to } \\
\text { family/ } \\
\text { relative }\end{array}$ & & \\
\hline \multicolumn{6}{|l|}{ Age of woman } \\
\hline $15-19$ & 38.5 & 47.1 & 49.4 & 30.1 & 595 \\
\hline $20-24$ & 56.8 & 66.0 & 70.8 & 31.4 & 1032 \\
\hline $25-29$ & 60.2 & 70.1 & 75.7 & 30.9 & 1353 \\
\hline $30-34$ & 61.0 & 70.7 & 78.3 & 28.5 & 1049 \\
\hline $35-39$ & 62.7 & 72.0 & 79.8 & 29.1 & 1054 \\
\hline $40-44$ & 64.2 & 73.3 & 81.2 & 27.0 & 815 \\
\hline $45-49$ & 63.9 & 73.4 & 82.0 & 23.8 & 717 \\
\hline \multicolumn{6}{|l|}{ Residence } \\
\hline Urban & 69.4 & 81.2 & 82.6 & 36.5 & 2422 \\
\hline Rural & 53.2 & 61.4 & 70.6 & 20.9 & 4193 \\
\hline \multicolumn{6}{|l|}{ Education } \\
\hline No education & 55.2 & 62.6 & 71.7 & 21.9 & 4070 \\
\hline Primary & 63.6 & 76.7 & 78.3 & 26.0 & 1725 \\
\hline Secondary+ & 69.0 & 82.7 & 84.4 & 51.1 & 820 \\
\hline \multicolumn{6}{|l|}{ Employment } \\
\hline Not employed & 54.0 & 63.9 & 71.6 & 26.4 & 5370 \\
\hline Employed & 80.9 & 88.8 & 89.2 & 27.4 & 1245 \\
\hline \multicolumn{6}{|c|}{ Household econ. status } \\
\hline Low & 47.7 & 54.2 & 66.4 & 22.4 & 2616 \\
\hline Medium & 65.9 & 75.8 & 78.8 & 24.1 & 2726 \\
\hline High & 68.1 & 83.1 & 84.5 & 40.6 & 1273 \\
\hline Total & 59.3 & 68.7 & 75.0 & 26.6 & 6615 \\
\hline
\end{tabular}

* Husband can beat his wife if she argues with him, if she goes outside without informing him, if she neglects the children, or if she refuses to have sex with him

\section{Descriptive analyses: women's autonomy and fertility preferences}

One very important indicator of women's ability to limit their number of children and of the prospect for future fertility decline is their desire to cease childbearing (PRB, 2006). The main focus of this section is to make a preliminary assessment of the relationship between proxy and direct measures of women's decision-making autonomy and fertility preferences using bivariate analysis. Odds ratios from multivariate logistic regression models are then used to interpret the effects of the former variables on the outcome variables. 


\subsection{Women's proxy and direct indicators of autonomy and desire for no more children}

Figure 3 shows the percentage distribution of married women who desire no more children according to women's demographic and socio-economic characteristics. Overall, 22\% of married women in Eritrea wish to stop childbearing. It is evident from Figure 3 that the proportion of women not wanting any more children is associated with almost all the socio-demographic variables. Women living in urban areas are more likely to terminate childbearing than those living in rural areas. Differentials in wanting no more children by educational attainment are insignificant, however. The proportions of uneducated women and women with some secondary or higher education who wish to limit childbearing are almost the same. As expected, women with high household economic status and who are employed are much more likely to limit childbearing compared with those who have low economic status and who are not employed. The proportion of women who said that they do not wish to have any more children increases as the number of living children increases. However, compared with other developing countries, the proportion of married women who wish to limit childbearing is small. For instance, in Vietnam $92 \%$ of women who had two living children said they did not wish to have any more children (PRB, 2006). In Eritrea, by contrast, that figure is only 14\%. Older women are also more likely to limit their childbearing compared with younger women. This is because the more children the woman has, the more likely she is to be older.

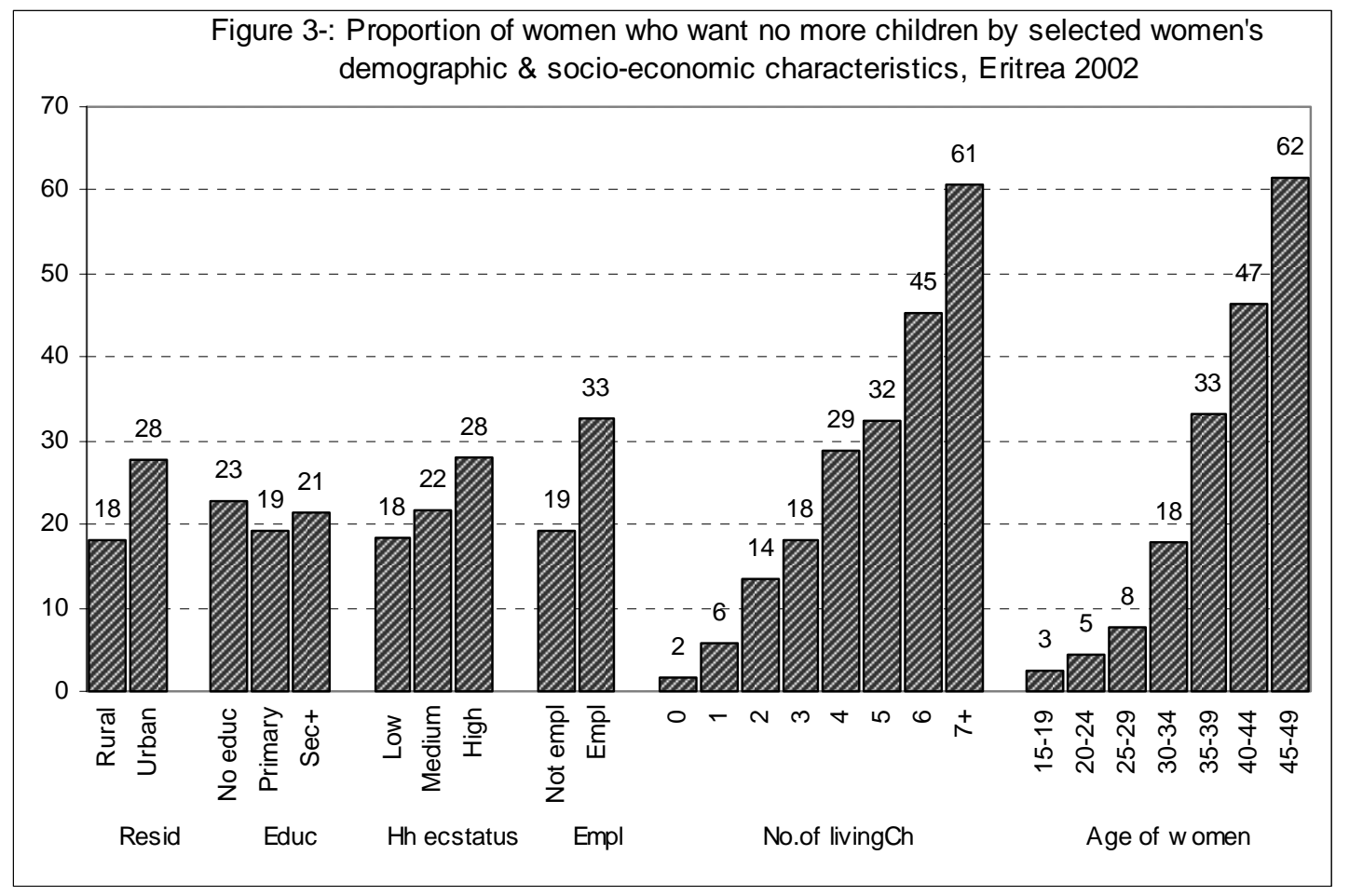

In terms of the autonomy variables (Figure 4), women who can make domestic decisions alone are more likely to wish to limit childbearing than women who make the decisions jointly with their husbands or with others in the household or than women who do not participate at all. Women who find wife beating justifiable are more likely to want more children than their counterparts who do not find wife beating justifiable. Women who discuss family planning with their partner are more likely to wanting no more children. 
Figure 4-: Proportion of women who want no more children by selected women's autonomy indicators, Eritrea 2002

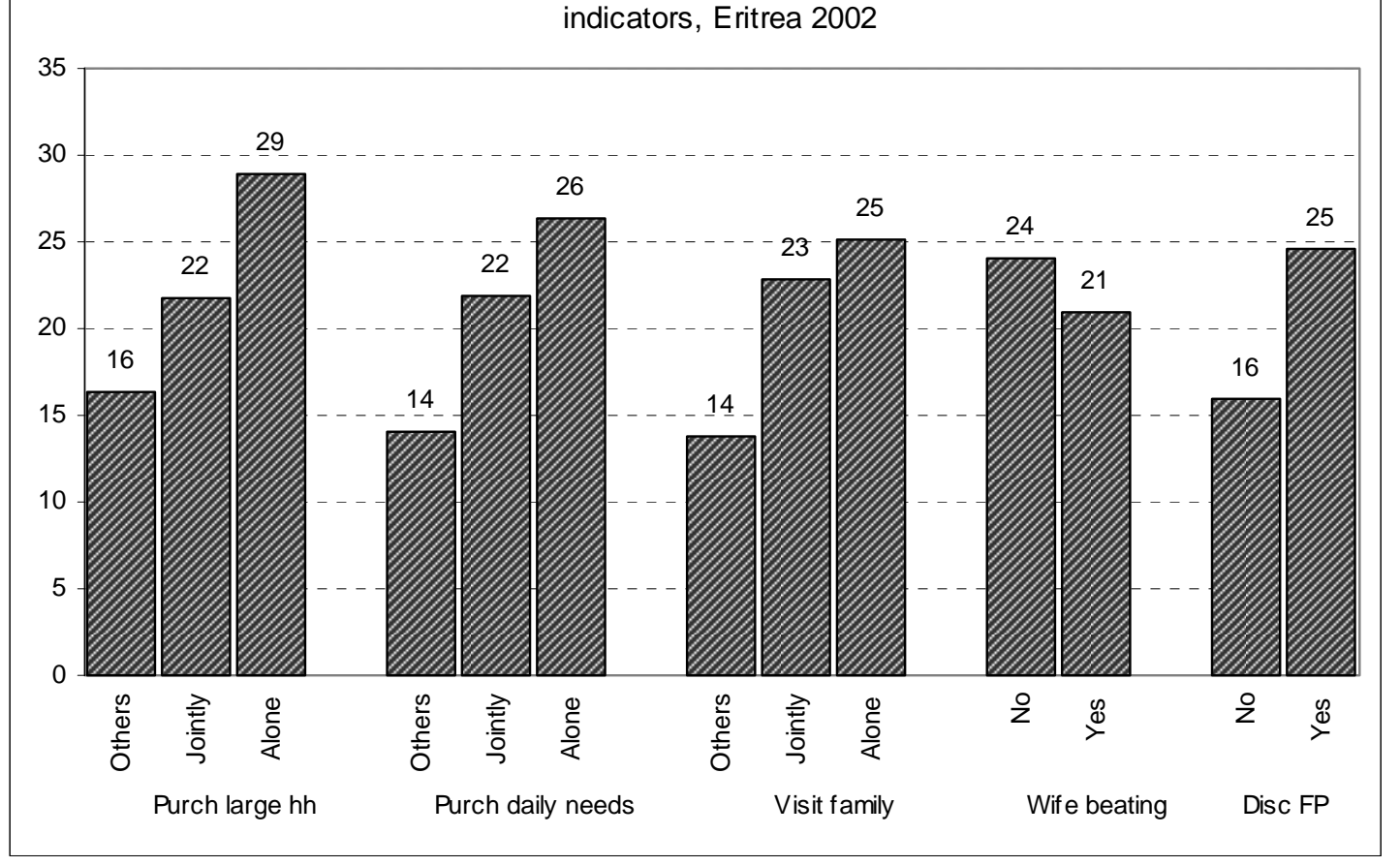

\subsection{Women's proxy and direct indicators of autonomy and desired family size}

Figure 5 shows the desired mean ideal number of children according to sociodemographic variables. The results show that urban women are less likely to have large ideal number of children than rural women. Educated women, employed women and women with high household economic status have lower desired family size compared with uneducated, unemployed and low household economic status, respectively. It is also observed that the mean ideal number of children increases with the number of living children, from 4.9 for women with no children to 8.1 for women with seven or more children. There is a direct relationship between age of women and ideal family size, where it increases from 4.8 for women age 15-19 to 5.6 for women 25-29 and 7.2 for women age 45-49. These patterns are consistent with expectations and literature (e.g., HIPS and Macro International Inc. 1997). The decline in mean family size from older to younger cohorts is related to a decline in fertility over time. 


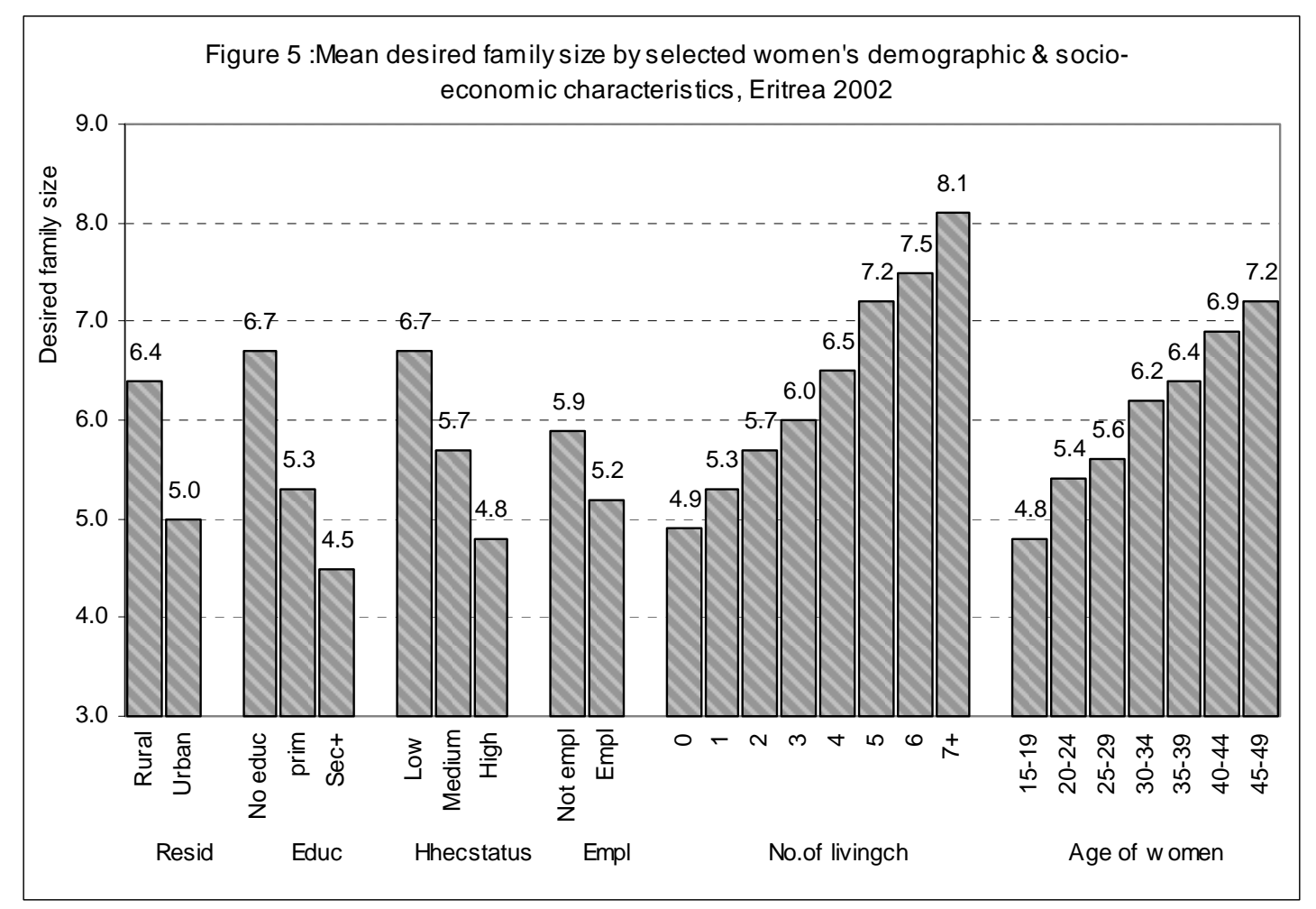

Overall, women's autonomy or final say in decision-making is weakly related to the mean ideal family size, and in most cases differences are not significant. As can be seen from Figure 6, the mean ideal number of children is lowest (5.7) for women who have the final say in decisions of making large or daily household purchases. The mean ideal family size is highest when decisions are made jointly. The relationship between the mean ideal number of children and the reasons for which women consider wife beating justified shows the expected pattern, the mean number is lower for women who believe that wife beating is not justified for any of the specified reasons (see section 1.3) than for women who agree with some reason. Women who discussed family planning with their partner are also more likely to have lower ideal family size than those who did not discuss family planning. 


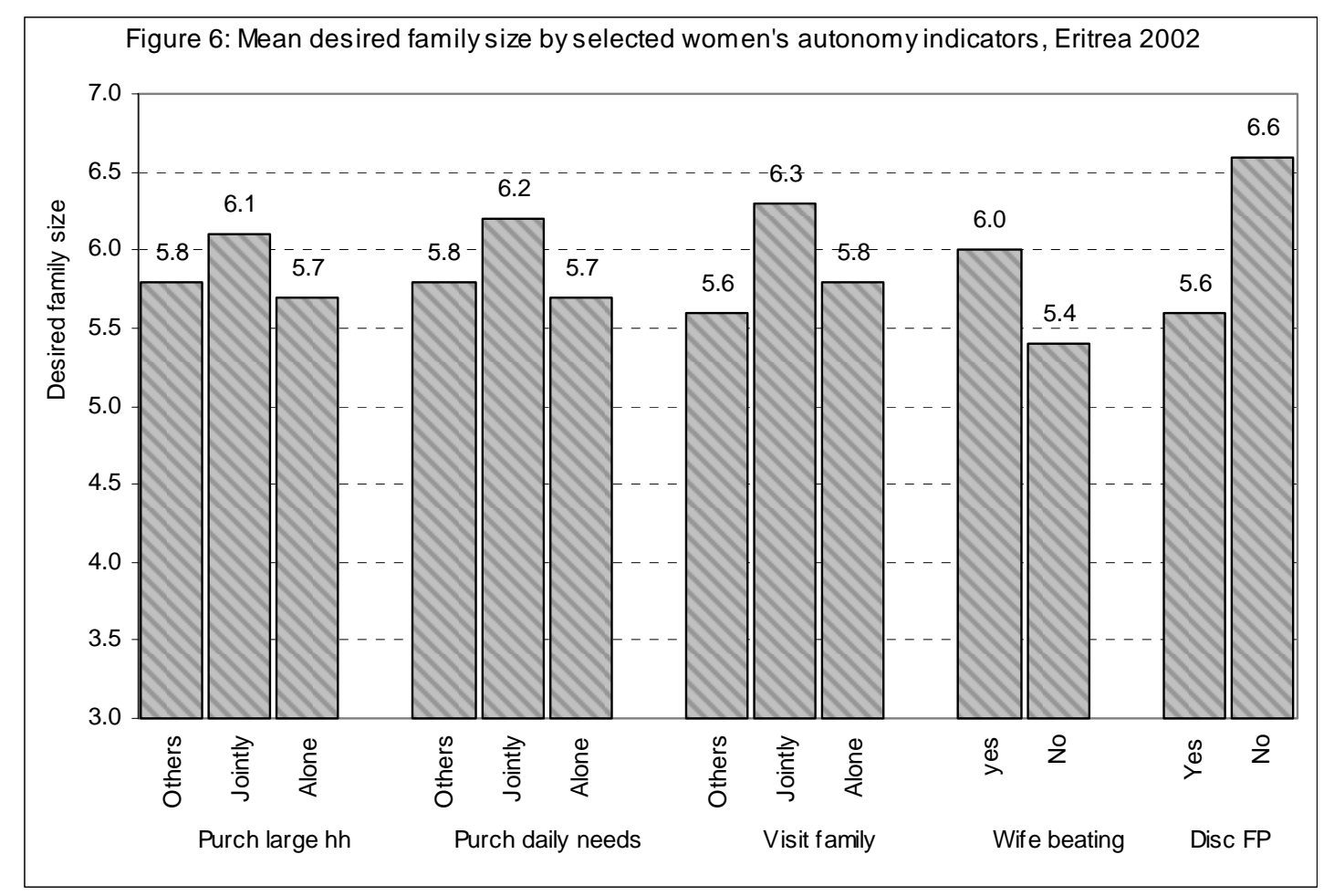

\section{Multivariate analysis}

\subsection{Relationship between women's autonomy and autonomy proxies}

As a first step towards assessing the link between women's autonomy indicators, autonomy proxy variables (educational attainment, household economic status and employment) and fertility preferences, it is important to look at the relationship between the autonomy and autonomy proxy variables. Two other variables: residence and age of women are included in this analysis as control variables. Each autonomy variable has two categories: not involved in decision-making and involved in decision-making.

All the proxy indicators included are found to be significantly associated with women's decision-making autonomy (see Table 5). Having some primary or higher education is positively associated with involvement in all decision-making autonomy. Compared with their uneducated counterparts, educated women are also more likely to discus family planning affairs with their partners. Higher levels of household wealth and employment are both associated with higher women's autonomy in decision-making. Place of residence is an important factor for decision-making, where living in rural areas reduces women's autonomy to purchase large items or daily needs, to visit relatives or friends, and to discuss family planning with their partner. Older women are more likely to be involved in household decision-making than younger women. But, age of women does not seem to have significant effect on family planning discussions. 
Table 5: Odds ratios for autonomy among women in Eritrea

\begin{tabular}{|c|c|c|c|c|}
\hline \multirow[b]{2}{*}{ Indicator } & \multicolumn{3}{|c|}{ Women involved in decision to } & \multirow{2}{*}{$\begin{array}{l}\text { Discussed } \\
\text { family planning } \\
\text { with partner }\end{array}$} \\
\hline & $\begin{array}{l}\text { Purchase large } \\
\text { household item }\end{array}$ & $\begin{array}{l}\text { Purchase daily } \\
\text { household needs }\end{array}$ & $\begin{array}{l}\text { Visit } \\
\text { families }\end{array}$ & \\
\hline \multicolumn{5}{|l|}{ Residence } \\
\hline Urban & 1 & 1 & 1 & 1 \\
\hline Rural & $0.74 * * *$ & $0.81^{* * *}$ & 0.93 & $0.62 * * *$ \\
\hline \multicolumn{5}{|l|}{ Education } \\
\hline No education & 1 & 1 & 1 & 1 \\
\hline Primary & $1.30 * * *$ & $1.70 * * *$ & $1.58 * * *$ & $2.92 * * *$ \\
\hline Secondary+ & $1.36^{* * *}$ & $1.70 * * *$ & $1.86 * * *$ & $5.32 * * *$ \\
\hline \multicolumn{5}{|c|}{$\begin{array}{l}\text { Household econ } \\
\text { status }\end{array}$} \\
\hline Low & 1 & 1 & 1 & 1 \\
\hline Medium & $1.70 * * *$ & $2.05 * * *$ & $1.60 * * *$ & $1.55 * * *$ \\
\hline High & $1.42 * * *$ & $2.32 * * *$ & $1.79 * * *$ & $1.51 * * *$ \\
\hline \multicolumn{5}{|l|}{ Employment } \\
\hline Not employed & 1 & 1 & 1 & 1 \\
\hline Employed & $2.42 * * *$ & $2.62 * * *$ & $1.72 * * *$ & $1.29 * * *$ \\
\hline \multicolumn{5}{|l|}{ Age of woman } \\
\hline$<20$ & 1 & 1 & 1 & 1 \\
\hline $20-29$ & $1.81 * * *$ & $1.98 * * *$ & $2.26 * * *$ & 1.00 \\
\hline $30-39$ & $2.00 * * *$ & $2.40 * * *$ & $3.06 * * *$ & $1.26 *$ \\
\hline $40-49$ & $2.27 * * *$ & $2.75 * * *$ & $3.78 * * *$ & 1.01 \\
\hline
\end{tabular}

* Factor level significant at $<10 \%$, ** significant at $<5 \%$, *** significant at $<1 \%$

\subsection{Women's autonomy as a correlate of wanting no more children}

The main question here is whether women's autonomy in decision-making has independent effects on the desire for no more children and if so, whether such effects are influenced by the proxy indicators and/or other socio-demographic variables. In Table 6, the odds ratios from two logistic regression models are shown, in which the dichotomy of want no more / want more children is the dependent variable. The first model includes only women's autonomy variables and the second model (full model) adds the proxy and other control variables.

It is clear from Table 6 that in households where women alone make the final decision on household purchases for daily needs, the likelihood for wanting no more children is higher than where the decision is made jointly or by the husband/others. This effect remains unchanged even after the proxy indicators are added. However, in the case of decisions on large household purchases, the likelihood for wanting no more children is higher if the husband or others have final say, though it is attenuated when the proxy variables are included. The odds ratios for decisions on visiting families or relatives indicate that if women jointly with husband or others make the final decision, the odds of wanting no more children is about $40 \%$ higher than if women alone or the husband or someone else makes the decision. But, this unexpected result vanishes when controlling for the proxy indicators. No differential effect on desire for no more children is observed between women who justified wife beating and those who did not. Husband-wife discussion on family planning is significantly related to wanting no more children, where women who discussed family planning with their husbands are about $40 \%$ more likely to want stop childbearing than those who never discussed. The odds of wanting no more children increase monotonically as the 
number of living children in the household increases. Residents in rural areas are less likely than residents of urban areas to want no more children. The desire for limiting childbearing is, somewhat surprisingly, the same between women with no education and those with secondary or higher education. There is a strong inverse relationship between desire for no more children and household economic status. Employment implies a higher propensity wanting to cease childbearing.

Table 6: Odds ratios from logistic regression models to predict lack of fertility desire: want no more children vs. wanting further children

\begin{tabular}{|c|c|c|}
\hline Variables & $\begin{array}{l}\text { Model with } \\
\text { autonomy only }\end{array}$ & Full model \\
\hline \multicolumn{3}{|c|}{ Decision on making large household purchases } \\
\hline Respondent & 1 & 1 \\
\hline Respondent jointly with husband or other & 1.08 & 0.82 \\
\hline Husband or other in household & $1.30 *$ & 0.97 \\
\hline \multicolumn{3}{|c|}{ Decision on making household purchases for daily needs } \\
\hline Respondent & 1 & 1 \\
\hline Respondent jointly with husband or other & 0.86 & 0.84 \\
\hline Husband or other in household & $0.63 * * *$ & $0.69 * * *$ \\
\hline \multicolumn{3}{|l|}{ Decision for visiting families or relatives } \\
\hline Respondent & 1 & 1 \\
\hline Respondent jointly with husband or other & $1.42 * * *$ & 1.18 \\
\hline Husband or other in household & 1.00 & 1.15 \\
\hline \multicolumn{3}{|l|}{ Wife beating } \\
\hline Yes & 1 & 1 \\
\hline No & 1.04 & 1.14 \\
\hline \multicolumn{3}{|l|}{ Discussed family planning with partner } \\
\hline Yes & 1 & 1 \\
\hline Never & $0.58 * * *$ & $0.62 * * *$ \\
\hline \multicolumn{3}{|l|}{ Number of living children } \\
\hline 0 & - & $0.01 * * *$ \\
\hline $1-2$ & - & $0.04 * * *$ \\
\hline 3-4 & - & $0.20 * * *$ \\
\hline $5+$ & - & 1 \\
\hline \multicolumn{3}{|l|}{ Residence } \\
\hline Urban & - & 1 \\
\hline Rural & - & $0.67 * * *$ \\
\hline \multicolumn{3}{|l|}{ Education } \\
\hline No education & - & 1 \\
\hline Primary & - & 0.83 \\
\hline Secondary + & - & 1.02 \\
\hline \multicolumn{3}{|l|}{ Household economic status } \\
\hline Low & - & 1 \\
\hline Medium & - & $1.28^{* *}$ \\
\hline High & - & $1.98 * * *$ \\
\hline \multicolumn{3}{|l|}{ Employment } \\
\hline Not employed & - & 1 \\
\hline Employed & - & $1.61 * * *$ \\
\hline
\end{tabular}




\subsection{Women's autonomy as a correlate of desired family size}

It is evident from Table 7 (first model) that with the exception of physical mobility to visit families or relatives, women's decision-making autonomy decreases desired family size. For example, women in households where they have final say in making large household purchases and in making day-to-day household purchases (either alone or jointly with others) are less likely to have large desired family size than those in households where final decision is made by the husband or others. However, women's decision-making autonomy to visit families or friends is, unexpectedly positively related to large desired family size. In terms of women's status in society, women who feel that wife beating is not justified are about $20-40 \%$ less likely to demand large family size than their counterparts who feel that wife beating is justified. It is posited that husband-wife communication is significantly associated with less desire for large family size (Lasee and Becker 1997). Our results are consistent with this as women who claim to have ever-discussed family planning with their partners are found to have smaller desired family size than women who never discussed family planning.

The addition of the proxy variables does not change the effects of women's decisionmaking authority (see the full model). Women's decision-making autonomy remains important and statistically significant, although the size of the odds ratios of attitude towards wife beating and spousal discussion decreased slightly. The full model shows that the proxy and control variables are significantly associated with desired family size too. Desire for large number of children increases with the number of living children a woman has. As expected, women who live in rural areas have higher desired large family size compared with those living in urban areas. One would expect women's education to be negatively related to desired family size because female education is hypothesized to reduce preferences for children by changing traditional values, increasing the perceived costs of children and raising the awareness of alternative sources of satisfaction (Cochrane, 1979). And the odds ratios in the full model confirm this negative effect of women's education on demand for children. There is also a strong inverse relationship between desired family size and household wealth and employment. 
Table 7: Odds ratios from logistic regression model on desired (ideal) family size: 5+ children vs smaller family size

\begin{tabular}{|c|c|c|}
\hline Variables & $\begin{array}{l}\text { Model with } \\
\text { autonomy only }\end{array}$ & Full model \\
\hline \multicolumn{3}{|c|}{ Decision on making large household purchases } \\
\hline Respondent & 1 & 1 \\
\hline Respondent jointly with husband or other & 1.01 & 1.06 \\
\hline Husband or other in household & $1.33 * *$ & $1.27 * *$ \\
\hline \multicolumn{3}{|c|}{ Decision on making household purchases for daily needs } \\
\hline Respondent & 1 & 1 \\
\hline Respondent jointly with husband or other & $1.24 *$ & 0.92 \\
\hline Husband or other in household & $1.93 * * *$ & $1.39 * *$ \\
\hline \multicolumn{3}{|l|}{ Decision for visiting families or relatives } \\
\hline Respondent & 1 & 1 \\
\hline Respondent jointly with husband or other & 101 & 1.01 \\
\hline Husband or other in household & $0.66^{* *}$ & $0.70 * *$ \\
\hline \multicolumn{3}{|l|}{ Wife beating } \\
\hline Yes & 1 & 1 \\
\hline No & $0.59 * * *$ & $0.74 * * *$ \\
\hline \multicolumn{3}{|l|}{ Discussed family planning with partner } \\
\hline Yes & 1 & 1 \\
\hline Never & $1.82^{* * *}$ & $1.25^{* *}$ \\
\hline \multicolumn{3}{|l|}{ Number of living children } \\
\hline 0 & - & 1 \\
\hline $1-2$ & - & 1.09 \\
\hline 3-4 & - & $2.30 * * *$ \\
\hline $5+$ & - & $3.99 * * *$ \\
\hline \multicolumn{3}{|l|}{ Residence } \\
\hline Urban & - & 1 \\
\hline Rural & - & $1.26 * *$ \\
\hline \multicolumn{3}{|l|}{ Education } \\
\hline No education & - & 1 \\
\hline Primary & - & $0.79 * *$ \\
\hline Secondary+ + & - & $0.44 * * *$ \\
\hline \multicolumn{3}{|l|}{ Household economic status } \\
\hline Low & - & 1 \\
\hline Medium & - & $0.83^{*}$ \\
\hline High & - & $0.51 * * *$ \\
\hline \multicolumn{3}{|l|}{ Employment } \\
\hline Not employed & - & 1 \\
\hline Employed & - & $0.70^{* * *}$ \\
\hline
\end{tabular}




\subsection{Women's autonomy as a correlate of ever-use of modern family planning methods}

Table 8 presents results from logistic regression models for ever-use of modern family planning. The findings indicate some significant, but contradictory effects of women's decision-making autonomy on ever-use of modern contraceptive methods. Women who make the final decision on large household purchases alone are least likely to have used modern contraception. However, women's decision-making autonomy in making day-to-day household purchases is positively related with ever use of modern contraception. In terms of visiting families or relatives, women who have a final say alone and/or jointly with their partner or others are more likely to have used modern family planning. Women who feel that wife beating is not justified are more likely to have used family planning, but this effect is reversed after the proxy indicators of women's status and other variables are controlled.

Table 8: Odds ratios of ever use of modern contraceptive methods

\begin{tabular}{|c|c|c|}
\hline Variables & $\begin{array}{l}\text { Model with } \\
\text { autonomy only }\end{array}$ & $\begin{array}{l}\text { Full } \\
\text { model }\end{array}$ \\
\hline \multicolumn{3}{|c|}{ Decision on making large household purchases } \\
\hline Respondent & 1 & 1 \\
\hline Respondent jointly with husband or other & $1.65^{* * *}$ & $1.48^{* * *}$ \\
\hline Husband or other in household & $1.49 * * *$ & $1.48^{* * *}$ \\
\hline \multicolumn{3}{|c|}{ Decision on making household purchases for daily needs } \\
\hline Respondent & 1 & 1 \\
\hline Respondent jointly with husband or other & $0.40 * * *$ & $0.51^{* * *}$ \\
\hline Husband or other in household & $0.34 * * *$ & $0.55^{* * *}$ \\
\hline \multicolumn{3}{|l|}{ Decision for visiting families or relatives } \\
\hline Respondent & 1 & 1 \\
\hline Respondent jointly with husband or other & $1.21 *$ & 1.20 \\
\hline Husband or other in household & $0.77 *$ & $0.75^{*}$ \\
\hline \multicolumn{3}{|l|}{ Wife beating } \\
\hline Yes & 1 & 1 \\
\hline No & $1.16^{*}$ & $0.79 * *$ \\
\hline \multicolumn{3}{|l|}{ Discussed family planning with partner } \\
\hline Yes & 1 & 1 \\
\hline Never & $0.18 * * *$ & $0.30 * * *$ \\
\hline \multicolumn{3}{|l|}{ Residence } \\
\hline Urban & - & 1 \\
\hline Rural & - & $0.50 * * *$ \\
\hline \multicolumn{3}{|l|}{ Education } \\
\hline No education & - & 1 \\
\hline Primary & - & $2.00^{* * *}$ \\
\hline Secondary + & - & $2.26^{* * *}$ \\
\hline \multicolumn{3}{|l|}{ Household economic status } \\
\hline Low & - & 1 \\
\hline Medium & - & $1.83^{* * *}$ \\
\hline High & - & $2.89 * * *$ \\
\hline \multicolumn{3}{|l|}{ Employment } \\
\hline Not employed & - & 1 \\
\hline Employed & - & $1.45^{* * *}$ \\
\hline
\end{tabular}

* Factor level significant at $<10 \%$, $* *$ significant at $<5 \%$, *** significant at $<1 \%$ 
There is a very strong direct association between husband-wife discussion on family planning and ever-use of modern family planning. Women who discussed family planning are 3 to 5 times more likely to have used modern contraceptive methods.

From the full model, it is observed that the effects of women's decision-making autonomy largely remain the same. However, in the case of attitude toward wife beating, the results reversed in magnitude. Unexpectedly, women who disagree with wife beating have significantly lower odds of having used modern contraception. All the women's status proxy indicators are associated with ever-use of contraception. Urban resident women are more likely to have used than rural residents. As compared with women who have no education, low economic status and unemployed, women who are educated, who have high household wealth and those employed, are more likely to have used modern methods of contraception.

\section{Discussion and conclusion}

An increase in women's decision-making autonomy is recognized as important factor in reducing fertility through at least two main pathways: its negative association with desired family size and its positive association with women's ability to meet their own family size goals through the effective use of contraception. However, while the literature suggests that women's decision-making autonomy is important, little is known about the effects of women's autonomy on fertility and fertility preferences in Eritrea. The main objective of this study is to determine the effects of women's decision-making autonomy on fertility preferences and ever-use of contraception in the country and to explore whether such effects are influenced by the proxy indicators of women's autonomy. Overall, our findings demonstrate that women's decisionmaking autonomy variables are important predictors of fertility preferences and everuse of contraception although the predicting power may differ by the type of outcome. The results also confirm that, in most cases, the effects are independent of the proxy indicators of education, household wealth, and employment and of other sociodemographic variables.

This paper shows that in Eritrea the majority of married women report relatively high levels of autonomy, although this varies by their level of education, employment status, household wealth and residence. Women who are more educated, employed and with high household wealth are found to have higher levels of decision-making autonomy. These variables are also found to be significantly related with spousal communication on family planning, where educated, employed, and high economic status women have higher ability to discuss about family planning with their partner than other women. The place of residence is important too; living in urban areas improves women's autonomy.

This study also shows that different dimensions of women's autonomy are important correlates of fertility preferences and ever-use of contraception and in most cases, their importance is not affected by the proxy indicators and other socio-demographic factors included in the analysis. This confirms the claim that women's decisionmaking autonomy is important for reproductive preferences (Kishor, 2005). Although all decision-making autonomy factors are found to be important, the ability of women to be involved in the decision to make day-to-day purchases and spousal 
communication on family planning are found to be the most influential of the autonomy factors in fertility preferences and ever-use of contraception. Women who feel that wife beating is not justifiable are observed to be more likely to wish smaller family size than women who feel that wife beating is justifiable. We also note that not all effects appear entirely consistent with our expectations.

In terms of the proxy indicators, the results generally support the hypothesis that women with education, high household wealth and those employed are more likely to prefer small family size and to use contraceptive methods. The results also indicate that most of the effects of these proxy indicators on fertility preferences or contraceptive use are not mediated by the more direct measures of women's autonomy. Further, women who live in urban areas have substantially more desire to limit childbearing, have smaller family size and having used family planning than do women living in rural areas.

Our findings, therefore, have implications not only for fertility preferences research, but also for population policies and programs in Eritrea in particular and sub-Saharan Africa in general. Although our study is limited to Eritrea, the situation of women is not entirely different from what prevails in many other patriarchal societies in Africa. The results confirm that women's decision-making autonomy is important determinant of fertility preferences and contraceptive use. They also show that the proxy variables including education, household wealth and employment significantly are related to both women's decision-making autonomy and to the outcome variables. Thus, the results strengthen the view that both women's decision-making autonomy and autonomy proxies are needed in order to understand fertility preferences. They do not confirm the view that the autonomy proxies affect fertility preferences only through the autonomy variables nor do they confirm that the proxies are the sole determinants of fertility preferences and contraceptive use. Thus, policies and programs designed to reduce fertility must incorporate both women's decision-making autonomy and autonomy proxies. Current policies on fertility in most African countries are heavily oriented towards female education and employment and need to be redirected to include women's decision-making autonomy profiles too. Although the data used are cross-sectional, the results have some implications on future family size, in that if Eritrean women are empowered their desire for large family size will decline and hence fertility will decline.

While we found support for the hypotheses of this study, there are some limitations too. In particular, understanding the role of women's decision-making autonomy in fertility preferences and decisions may be problematic because of the difficulty in formulating an appropriate autonomy construct. Some authors argue that "autonomy" is not a useful concept in developing countries (Jeffery and Jeffery 1997). Moreover, the meaning of the word autonomy is hardly ever understood by women interviewed in surveys and translations of the word always carry a negative connotation (Jeffery and Jeffery 1997). This may suggest that there is a need for more qualitative research on the topic, preferably also formulated by researchers who are native to the country they are studying. 


\section{Acknowledgements}

I undertook this study while I was a guest researcher at the Max Planck Institute for Demographic Research, Rostock, Germany, during December 2006-April 2007. I would like to express my appreciation and gratitude to Prof. Jan M. Hoem for providing me a research fellowship. I am also very grateful to Dr Gunnar Andersson for the valuable comments, encouragement, and editorial work he provided.

\section{References}

Balk D. 1994. Individual and community aspects of women's status and fertility in rural Bangladesh. Population Studies, 48: 21-45.

Balk D. 1997. Defying gender norms in rural Bangladesh: A social Demographic Analysis. Population Studies, 51(2): 153-172

Basu, A.M. 1992. Culture, the Status of Women and Demographic Behaviour. Oxford: Clarendon.

Basu A.M. and Koolwal G.B. 2005. Two concepts of female employment: Some leads from DHS data on women's status and reproductive health, In Kishor, S. (ed.) 2005. A Focus on Gender: Collected Papers on Gender Using DHS Data. Calverton, Maryland, USA: ORC Macro.

Caldwell J.C. 1986. Routes to low mortality in poor countries. Population and Development Review, 12: 171-220.

Caldwell J.C. and Caldwell P. 1985. The cultural forces tending to sustain high fertility in tropical Africa. Washington DC: World Bank, Population, Health and Nutrition Department, PNH Technical Note, 66pp.

Cochrane S.H. 1979. Fertility and education: What do we really know? World Bank Staff Occasional Papers 26. Washington, D.C.: Johns Hopkins University Press.

Desai S. and Johnson K. 2005. Women’s decision-making and child health: Familial and social hierarchies, In Kishor, S. (ed.) 2005. A Focus on Gender: Collected Papers on Gender Using DHS Data. Calverton, Maryland, USA: ORC Macro.

Dharmalingam A. and Morgan S.P. 1996. Women's work, autonomy, and birth control. Evidence from two south Indian villages. Population Studies, 50: 187-201

Jejeebhoy S. 1991. Women's status and fertility: Successive cross-sectional evidence from Tamil Nadu, India 1970-80. Studies in Family Planning, 22(4): 217-230

Jejeebhoy S.and Sathar Z. 2001. Women's autonomy in Indian and Pakistan: The influence of religion and region. Population and Development Review, 27: 687-712

Jeffery, R and Jeffery P. 1997. Population, Gender and Politics: Demographic Change in Rural North India. Cambridge: Cambridge University Press.

Gage A. J. 1995. Women's socio-economic position and contraceptive behavior in Togo. Studies in Family Planning, 26(5):264-277.

GSE and UNICEF 2001. Towards Realizing Child Rights in Eritrea: An Analysis of the Situation of Children and Women. Asmara. 
HIPS (Hacettepe University, Institute of Population Studies) and Macro International Inc. 1997. Fertility trends, women's status, and reproductive expectations in Turkey: Results of further analysis of the 1993 Turkish Demographic and Health Survey. Calverton, Maryland: HIPS and MI.

Kishor, S. (ed.) 2005. A Focus on Gender: Collected Papers on Gender Using DHS Data. Calverton, Maryland, USA: ORC Macro.

Kishor S. and Neitzel K. 1996. The status of women: Indicators for twenty-five countries. DHS Comparative Studies No. 21. Calverton, Maryland: Macro International Inc.

Kritz M.M. and Makinwa-Adebusoye, P. 1999. Determinants of women's decisionmaking authority in Nigeria. Sociological Forum, 14(3): 397-492.

Lasee A. and Becker S. 1997. Husband-wife communication about family planning contraceptive use in Kenya. International Family Planning Perspective, 23(10): 1520.

Malhotra A., Vanneman R and Kishor S. 1995. Fertility dimensions of patriarchy and development in India. Population and Development Review, 21(2): 281-305

Makinwa-Adebusoye, P. and Mary M. Kritz, 1997. Reproductive decision-making in Nigeria. African Population Studies, 12(1): 89-108.

Mason, K. O. 1986. The status of women: Conceptual and methodological issues in demographic studies. Sociological Forum, 1(2): 284-300.

Mason, K. O. 1989. The impact of women's social position on fertility in Developing countries. In Stycos J. M. (ed.) 1989. Demography as an Interdiscipline. Transaction Publishers, New Brunswick and Oxford.

Mason, K.O. 1994. Conceptualizing and measuring women's status. Paper presented at the annual meeting of the Population Association of America. Miami, Florida.

Morgan N. and Niraula B. 1995. Gender inequality and fertility in two Nepali villages. Population and Development Review, 21(3): 541-561.

NSEO(National Statistics and Evaluation Office [Eritrea]) and ORC Macro Inc. 2003. Eritrea Demographic and Health Surveys 2002. Calverton, Maryland, USA

Okojie C.E.E 1995. The relationship between women's status, proximate determinants and fertility in Nigeria. In Makinwa P. and Jensen A.M.(eds.) 1995. Women's Position and Demographic Change in sub-Saharan Africa. IUSSP. Belgique.

PRB (Population Reference Bureau) 2005. Women in 2005: Are they making progress. Website: http:lwww.prb.org

PRB (Population Reference Bureau) 2006. World Population highlights. Web-site: http:lwww.prb.org

Qiaozhun L. and Chuzhu Z. 1997. Women's status and fertility: Study from individual and community aspects. Paper presented at the IUSSP International Population Conferences, 11-17 October 1997. Beijing, China

Robson E. 1995. The economic activities and status of rural Muslim Hausa women in Northern Nigeria. In Makinwa P. and Jensen A. (eds.) 1995. Women's Position and Demographic Change in sub-Saharan Africa. IUSSP, Belgium 
Safilios-Ruthschild C. 1990. Women's income profile as a key indicator of women's status for the understanding of changing fertility behavior in rural Kenya. Genus, 46(3-4): 31-34.

Tfaily R. 2004. Do women with higher autonomy have lower fertility? Evidence from Malaysia, the Philippines and Thailand. Genus, LX(2): 7-32

UN(United Nations) 1995. Summary of the Program of Action of the International Conference on Population and Development. New York: United Nations.

Vlassoff, C. 1992. Progress and stagnation: changes in fertility and women's position in an Indian village. Population Studies, 46(2): 195-212.

Weinberger, M.B., Lloyd, C. and Blanc A. 1989. Women's education and fertility: A decade of change in four Latin American countries. International Family Planning Perspectives, 15: 4-28. 